\title{
Some Strong and $\Delta$ - Convergence Results in Hyperbolic Spaces
}

\author{
Preety Malik \\ Department of Mathematics, \\ Government College for Women, \\ Rohtak-124001 (India)
}

\begin{abstract}
The aim of this paper is to prove some strong and $\Delta$ convergence results for modified Khan et. al. iterative procedures using total asymptotically quasi-nonexpansive mappings in Hyperbolic spaces. The results are the generalization and extension of some results of Agarwal et. al. [12], Cho and Abbas [17], Basarir and Sahin [10], Chang et. al. [18], Agarwal et. al. [12], Aggarwal and Chugh [11], Khan et. al. [15], Sahin and Basarir [1].
\end{abstract}

\section{Mathematics Subject Classifications} 47H09, 47H10, 54H25.

\section{Keywords}

Hyperbolic spaces, $\Delta$-convergence, strong convergence, total asymptotically quasi nonexpansive mappings, common fixed point, Iterative procedures.

\section{INTRODUCTION}

In 1970, Takahashi [25] introduced the concept of convexity in metric space $(X, d)$ as follows:

Definition 1.1 [25] A map $W: X^{2} \times[0,1] \rightarrow X$ is a convex structure in $X$ if

$$
d(u, W(x, y, \lambda)) \leq \lambda d(u, x)+(1-\lambda) d(u, y)
$$

for all $x, y, u \in X$ and $\lambda \in[0,1]$. A metric space $(X, d)$ together with a convex structure $\mathrm{W}$ is known as convex metric space and is denoted by $(X, d, W)$. A nonempty subset $C$ of a convex metric space is convex if $W(x, y, \lambda) \in C$ for all $x, y \in C$ and $\lambda \in[0,1]$.

All normed spaces and their subsets are the examples of convex metric spaces. But there are many examples of convex metric spaces which are not imbedded in any normed space, (see Takahashi [25]).After that several authors extended this concept in many ways. One such convex structure is hyperbolic space which was introduced by Kohlenbach [23] as follows:

Definition 1.2 [23] A hyperbolic space $(X, d, W)$ is a metric space $(X, d)$ together with a convexity mapping $W: X^{2} \times[0,1] \rightarrow X$ satisfying

(W1) $d(z, W(x, y, \lambda)) \leq(1-\lambda) d(z, x)+\lambda d(z, y)$

(W2) $d\left(W\left(x, y, \lambda_{1}\right), W\left(x, y, \lambda_{2}\right)\right)=\left|\lambda_{1}-\lambda_{2}\right| d(x, y)$

(W3) $W(x, y, \lambda)=W(y, x, 1-\lambda)$

(W4) $d(W(x, z, \lambda), W(y, w, \lambda)) \leq(1-\lambda) d(x, y)+\lambda d(z, w)$

for all $x, y, z, w \in X$ and $\lambda, \lambda_{1}, \lambda_{2} \in[0,1]$.
Clearly every hyperbolic space is convex metric space but converse need not true. For example, if $X=R$ (the set of reals), $\quad W(x, y, \lambda)=\lambda x+(1-\lambda) y \quad$ and define $d(x, y)=\frac{|x-y|}{1+|x-y|}$ for $x, y \in R$, then $(X, d, W)$ is a convex metric space but not a hyperbolic space.

The concept of $\Delta$-convergence in a metric space was introduced by Lim [20] and its analogue in CAT(0) spaces was investigated by Dhompongsa and Panyanak [14]. In this paper, some strong and $\Delta$-convergence results for total asymptotically quasi-nonexpansive mappings using modified Khan et. al. iterative procedure of total asymptotically quasi nonexpansive mappings in hyperbolic spaces are established. The results obtained extend and generalize some results of Sahin and Basarir[1], Basarir and Sahin[10],Chang et. al.[18], Agarwal et. al. [12], Aggarwal and Chugh[11], Khan et. al. [15], Khan, Cho and Abbas [17] and Khan and Abbas [16].

Now, some well known concepts and results are given as:

The class of Hyperbolic spaces includes normed spaces,

CAT(0) spaces, Hadmard manifolds, R-trees and Hilbert balls.

A hyperbolic space $(X, d, W)$ is said to be uniformly convex [21] if for all $u, x, y \in X$, $r>0$ and $\varepsilon \in(0,2]$, there exists a $\delta \in(0,1]$ such that $d\left(W\left(x, y, \frac{1}{2}\right), u\right) \leq(1-\delta) r$, whenever $d(x, u) \leq r, d(y, u) \leq r$ and $d(x, y) \geq \varepsilon r$.

A $\operatorname{map} \eta:(0, \infty) \times(0,2] \rightarrow(0,1]$ which provides such a $\delta=\eta(r, \varepsilon)$ for $u, x, y \in X, r>0$ and $\varepsilon \in(0,2]$ is called modulus of uniform convexity of X. We call $\eta$ to be monotone if it decreases with $\mathrm{r}$ (for a fixed $\varepsilon$ ).

A sequence $\left\{x_{n}\right\}$ in $(X, d)$

is Fejer monotone with respect to a subset $\mathrm{K}$ of $\mathrm{X}$ if $d\left(x_{n}, x\right) \leq d\left(x_{n-1}, x\right)$ for all $x \in K$.

Let $\left\{x_{n}\right\}$ be a bounded sequence in a metric space $\mathrm{X}$. We define a functional $r\left(.,\left\{x_{n}\right\}\right): X \rightarrow R^{+} \quad$ by $r\left(x,\left\{x_{n}\right\}\right)=\limsup _{n \rightarrow \infty} d\left(x, x_{n}\right)$ for all $x \in K$.The asymptotic radius of $\left\{x_{n}\right\}$ with respect to $K \subseteq X$ is defined as, $r\left(\left\{x_{n}\right\}\right)=\inf \left\{r\left(x,\left\{x_{n}\right\}\right): x \in K\right\}$.

A point $y \in K$ is called the asymptotic centre of $\left\{x_{n}\right\}$ with respect to $K \subseteq X$ if 
$r\left(y,\left\{x_{n}\right\}\right) \leq r\left(x,\left\{x_{n}\right\}\right)$ for all $x \in K$.The set of all asymptotic centres of $\left\{x_{n}\right\}$ is denoted by $A\left(\left\{x_{n}\right\}\right)$.

A sequence $\left\{x_{n}\right\}$ in $\mathrm{X}$ is said to $\Delta$-converge to $x \in X$ if $\mathrm{x}$ is the unique asymptotic centre of $\left\{u_{n}\right\}$ for every subsequence $\left\{u_{n}\right\}$ of $\left\{x_{n}\right\}$ [25]. In this case, we write $\mathrm{x}$ as $\Delta-$ limit of $\left\{x_{n}\right\}$, i.e., $\Delta-\lim _{n} x_{n}=x$.

Also $\Delta-$ convergence coincides with weak convergence in Banach spaces with opial's property [22].

It is known that uniformly convex Banach spaces and even CAT(0) spaces have the property that 'bounded sequences have unique asymptotic centres with respect to closed convex subsets.' The following lemma is due to Leustean [9] and ensures that this property also holds in a complete uniformly convex hyperbolic space.

Lemma1.3 [9] Let $(\mathrm{X}, \mathrm{d}, \mathrm{W})$ be a complete uniformly convex hyperbolic space with monotone modulus of uniform convexity $\eta$. Then every bounded sequence $\left\{x_{n}\right\}$ in $X$ has a unique asymptotic centre with respect to any nonempty closed convex subset $\mathrm{K}$ of $\mathrm{X}$.

Definition 1.4. Let $C$ be nonempty subset of a hyperbolic space $X$ and $T: C \rightarrow C$ be a mapping and let $F_{T}$ be the set of fixed points of $\mathrm{T}$. Then $\mathrm{T}$ is called

a) Uniformly L-Lipschitzian if there exists a constant $\mathrm{L}>0$ such that

$$
d\left(T^{n} x, T^{n} y\right) \leq L d(x, y) \quad \text { for }
$$$$
\text { all } x, y \in C, n \in N \text {. }
$$

b) nonexpansive if $d(T x, T y) \leq d(x, y) \quad$ for all $x, y \in C$.

c) quasi-nonexpansive[19] if $\quad d(T x, p) \leq d(x, p)$ for all $x \in C, p \in F(T)$.

d) asymptotically nonexpansive[7] if for a sequence $\left\{k_{n}\right\} \subset[1, \infty)$ with $\quad \lim _{n \rightarrow \infty} k_{n}=1$, we have $d\left(T^{n} x, T^{n} y\right) \leq k_{n} d(x, y)$ for all $x, y \in C, n \in N$.

e) asymptotically quasi-nonexpansive[8] if for a sequence $\left\{k_{n}\right\} \subset[1, \infty)$ with $\lim _{n \rightarrow \infty} k_{n}=1$, we have $d\left(T^{n} x, p\right) \leq k_{n} d(x, p)$ for all $x \in C, p \in F(T), n \in N$.

f) nearly asymptotically nonexpansive if there exists constants $\quad a_{n} \in[0,1), k_{n} \geq 0 \quad$ with $\lim _{n \rightarrow \infty} a_{n}=0, \eta\left(T^{n}\right) \geq 1, \lim _{n \rightarrow \infty} \eta\left(T^{n}\right)=0 \quad$ (where $\eta\left(T^{n}\right)$ denotes the infimum of constants $\left.k_{n}\right)$ such that

$$
\begin{aligned}
& d\left(T^{n} x, T^{n} y\right) \leq k_{n}\left(d(x, y)+a_{n}\right) \\
& \text { for all } x, y \in C, n \in N .
\end{aligned}
$$

g) total asymptotically nonexpansive[18] if there exist non-negative real sequences $\left\{\mu_{n}\right\},\left\{v_{n}\right\}$ with $\mu_{n} \rightarrow 0, v_{n} \rightarrow 0$, and a strictly increasing continuous function $\zeta:[0, \infty) \rightarrow[0, \infty)$ with $\zeta(0)=0$ such that

$$
\begin{aligned}
& \quad d\left(T^{n} x, T^{n} y\right) \leq d(x, y)+v_{n} \zeta(d(x, y))+\mu_{n} \\
& \text { for all } x, y \in C, n \in N .
\end{aligned}
$$

h) total asymptotically quasi-nonexpansive mapping if there exist non-negative real sequences $\left\{\mu_{n}\right\},\left\{v_{n}\right\}$ with $\mu_{n} \rightarrow 0, v_{n} \rightarrow 0$, and a strictly increasing continuous function $\zeta:[0, \infty) \rightarrow[0, \infty)$ with $\zeta(0)=0$ such that $d\left(T^{n} x, p\right) \leq d(x, p)+v_{n} \zeta(d(x, p))+\mu_{n} \quad$ for all $x \in C, p \in F(T), n \in N$.

i) semi-compact if for a sequence $\left\{x_{n}\right\}$ in $C$ with $\lim _{n \rightarrow \infty} d\left(x_{n}, T x_{n}\right)=0$, exists a subsequence $\left\{x_{n_{k}}\right\}$ of $\left\{x_{n}\right\}$ such that $\left\{x_{n_{k}}\right\}$ converges strongly to a point $p \in C$.

Remark 1.5 It can be clearly seen that the class of total asymptotically quasi-nonexpansive mappings includes the classes of total asymptotically nonexpansive, nearly asymptotically nonexpansive, asymptotically quasinonexpansive, asymptotically nonexpansive, quasinonexpansive and nonexpansive mappings. But the converse of each may not be true (see [8],[18] and [24]).

Lemma 1.6. [6] Let $\left\{a_{n}\right\},\left\{b_{n}\right\}$ and $\left\{\delta_{n}\right\}$ be sequences of nonnegative real numbers such that for all $n \in N$

$$
a_{n+1} \leq\left(1+\delta_{n}\right) a_{n}+b_{n},
$$

If $\sum_{n=1}^{\infty} \delta_{n}<\infty$ and $\sum_{n=1}^{\infty} b_{n}<\infty$ then $\lim _{n \rightarrow \infty} a_{n}$ exists.

\section{Lemma 1.7 [2] Let $(X, d, W)$}

be a uniformly convex hyperbolic space with monotone mod ulus of uniform convexity $\eta$. Let $x \in X$ and $\left\{a_{n}\right\}$ be a sequence in $[\mathrm{b}, \mathrm{c}]$ for some $b, c \in[0,1]$. If $\left\{w_{n}\right\}$ and $\left\{z_{n}\right\}$ are sequences in $\mathrm{X}$ such that $\limsup _{n \rightarrow \infty} d\left(w_{n}, x\right) \leq r$, $\limsup _{n \rightarrow \infty} d\left(z_{n}, x\right) \leq r$ and $\lim _{n \rightarrow \infty} d\left(W\left(w_{n}, z_{n}, a_{n}\right), x\right)=r$ for some $r \geq 0$, then

$\lim _{n \rightarrow \infty} d\left(w_{n}, z_{n}\right)=0$.

Let $C$ be a nonempty subset of a Banach space $X$ and $T, S: C \rightarrow C$ be two mappings. In the sequel $\mathrm{F}$ denotes the set of common fixed points of the mappings $T$ and $S$.

Schu [5] defined the modified Mann iterative procedure which is a generalization of Mann iterative procedure,

$\left\{\begin{array}{l}x_{1}=x \in C, \\ x_{n+1}=\left(1-a_{n}\right) x_{n}+a_{n} T^{n} x_{n}, n \in N,\end{array}\right.$

where $\left\{a_{n}\right\}$ is in $(0,1)$. If $\mathrm{a}_{\mathrm{n}}=1$ for all $n \in N$, then it reduces to modified Picard iteration defined as

$$
\left\{\begin{array}{l}
x_{1}=x \in C, \\
x_{n+1}=T^{n} x_{n}, n \in N .
\end{array}\right.
$$

Tan and $\mathrm{Xu}[6]$ generalized Ishikawa iteration procedure and studied modified Ishikawa iteration procedure,

$$
\left\{\begin{array}{l}
x_{1}=x \in C, \\
x_{n+1}=\left(1-a_{n}\right) x_{n}+a_{n} T^{n} y_{n}, \\
y_{n}=\left(1-b_{n}\right) x_{n}+b_{n} T^{n} x_{n}, n \in N,
\end{array}\right.
$$


where $\left\{a_{n}\right\}$ and $\left\{b_{n}\right\}$ are in $(0,1)$. By taking $\mathrm{b}_{\mathrm{n}}=0$ for all $n \in N$ in (1.1.3), we obtain modified Mann iterative procedure (1.1.1).

In 2007, Agarwal et. al. [12] defined the modified S-iterative procedure in as follows:

$$
\left\{\begin{array}{l}
x_{1}=x \in C, \\
x_{n+1}=\left(1-a_{n}\right) T^{n} x_{n}+a_{n} T^{n} y_{n}, \\
y_{n}=\left(1-b_{n}\right) x_{n}+b_{n} T^{n} x_{n}, n \in N,
\end{array}\right.
$$

where $\left\{a_{n}\right\}$ and $\left\{b_{n}\right\}$ are in $[0,1]$. We note that (1.1.4) is independent of (1.1.3) (and hence of (1.1.1)).

Recently, Khan, Cho and Abbas [17] introduced modified Khan et.al. iterative procedure as follows:

$$
\left\{\begin{array}{l}
x_{1}=x \in C, \\
x_{n+1}=\left(1-a_{n}\right) T^{n} x_{n}+a_{n} S^{n} y_{n}, \\
y_{n}=\left(1-b_{n}\right) x_{n}+b_{n} T^{n} x_{n}, n \in N,
\end{array}\right.
$$

where $\left\{a_{n}\right\}$ and $\left\{b_{n}\right\}$ are in $(0,1)$.

Now the iterative scheme (1.1.5) is modified in hyperbolic spaces as follows:

Let $C$ be a nonempty subset of a hyperbolic space $X$ and $T, S$ : $C \rightarrow C$ be two mappings with $F \neq \phi$. Then the sequence $\left\{x_{n}\right\}$ generated by

$$
\left\{\begin{array}{l}
x_{1}=x \in C, \\
x_{n+1}=W\left(T^{n} x_{n}, S^{n} y_{n}, a_{n}\right) \\
y_{n}=W\left(x_{n}, T^{n} x_{n}, b_{n}\right), \quad n \in N,
\end{array}\right.
$$

where $\left\{a_{n}\right\}$ and $\left\{b_{n}\right\}$ are in $(0,1)$ is called modified Khan et. al iterative procedure and for $S=\mathrm{T}$, it reduces to the modified $\mathrm{S}$ iteration defined by Chugh et. al. [13] in hyperbolic spaces given as:

$$
\left\{\begin{array}{l}
x_{1}=x \in C, \\
x_{n+1}=W\left(T^{n} x_{n}, T^{n} y_{n}, \mathrm{a}_{n}\right) \\
y_{n}=W\left(x_{n}, T^{n} x_{n}, b_{n}\right), \quad n \in N,
\end{array}\right.
$$

where $\left\{a_{n}\right\}$ and $\left\{b_{n}\right\}$ are in $(0,1)$.

For $n=1$ in (1.1.6) then Khan et. al. iterative scheme defined by Khan et. al. [15] will be obtained as a special case of iterative procedure (1.1.6):

\section{MAIN RESULTS}

In this section, some strong and $\Delta$-convergence results of the modified khan et. al. iterative procedure (1.1.6) to a common fixed point of two total asymptotically quasi-nonexpansive mappings $\mathrm{T}$ and $\mathrm{S}$ in hyperbolic spaces are proved.

Let $\mathrm{T}, \quad S: C \rightarrow C$ be two total asymptotically quasinonexpansive mappings satisfying

$$
\begin{array}{lrrr}
d\left(T^{n} x, p\right) \leq d(x, p)+v_{n} \zeta(d(x, p))+\mu_{n} & & \text { and } \\
d\left(S^{n} x, p\right) \leq d(x, p)+v_{n} \zeta(d(x, p))+\mu_{n} & \text { for } & \text { all } \\
x \in C, p \in F(T), n \in N, \text { with } & \text { non-negative } & \text { real } & \text { sequences }
\end{array}
$$

$\left\{\mu_{n}\right\},\left\{v_{n}\right\}$ with $\mu_{n} \rightarrow 0, v_{n} \rightarrow 0$, and a strictly increasing continuous function $\zeta:[0, \infty) \rightarrow[0, \infty)$ with $\zeta(0)=0$.

From now onwards, the set of common fixed points of $T$ and $S$ is denoted by $F=\{p \in C: T p=p=S p\}$.

Lemma 2.1 Let $C$ be a nonempty closed convex subset of a hyperbolic space $X$ and $T, S: C \rightarrow C$ be two uniformly $L_{l}$ and $L_{2}$-Lipschitizian and total asymptotically quasi-nonexpansive mappings and $L=\max \left\{L_{1}, L_{2}\right\}$. Let $\left\{x_{n}\right\}$ be defined by iterative procedure (1.1.6) with $F \neq \phi$. If the following conditions are satisfied:

a) $\quad \sum_{n=1}^{\infty} v_{n}<\infty, \sum_{n=1}^{\infty} \mu_{n}<\infty, \sum_{n=1}^{\infty} a_{n}<\infty$;

b) there exists a constant $M^{*}>0$ such that $\zeta(r) \leq M^{*} r, r \geq 0$

c) $\left\{b_{n}\right\}$ is the sequence in $[0,1]$ :

d) $\sum_{n=1}^{\infty} \sup \left\{d\left(z, T^{n} z\right): z \in B\right\}<\infty$ for each bounded subset $B$ of $C$.

e) there exists constants $b, c \in(0,1) \quad$ with $0<b(1-c) \leq \frac{1}{2}$ such that $\left\{a_{n}\right\} \subset[b, c]$,

then

(i) $\quad \lim _{n \rightarrow \infty} d\left(x_{n}, q\right)$ exists for all $q \in F$.

(ii) $\quad \lim _{n \rightarrow \infty} d\left(x_{n}, T x_{n}\right)=0=\lim _{n \rightarrow \infty} d\left(x_{n}, S x_{n}\right)$.

Proof. Let $q \in F$. Then,

$$
\begin{gathered}
d\left(y_{n}, q\right)=d\left(W\left(x_{n}, T^{n} x_{n}, b_{n}\right), q\right) \\
\leq\left(1-b_{n}\right) d\left(x_{n}, q\right)+b_{n} d\left(T^{n} x_{n}, q\right) \\
\leq\left(1-b_{n}\right) d\left(x_{n}, q\right)+b_{n}\left\{d\left(x_{n}, q\right)+v_{n} \zeta\left(d\left(x_{n}, q\right)\right)+\mu_{n}\right\} \\
\leq\left(1+b_{n} v_{n} M^{*}\right) d\left(x_{n}, q\right)+b_{n} \mu_{n}
\end{gathered}
$$$$
\leq\left(1+v_{n} M^{*}\right) d\left(x_{n}, q\right)+\mu_{n}
$$

Now, using (2.1.1),

$$
\begin{gathered}
d\left(x_{n+1}, q\right)=d\left(W\left(T^{n} x_{n}, S^{n} y_{n}, a_{n}\right), q\right) \\
\leq\left(1-a_{n}\right) d\left(T^{n} x_{n}, q\right)+a_{n} d\left(S^{n} y_{n}, q\right) \\
\leq\left(1-a_{n}\right)\left\{d\left(x_{n}, q\right)+v_{n} \zeta\left(d\left(x_{n}, q\right)\right)+\mu_{n}\right\}+a_{n} L d\left(y_{n}, q\right) \\
\leq\left(1-a_{n}\right)\left\{d\left(x_{n}, q\right)+v_{n} \zeta\left(d\left(x_{n}, q\right)\right)+\mu_{n}\right\} \\
\quad+a_{n} L\left\{\left(1+v_{n} M^{*}\right) d\left(x_{n}, q\right)+\mu_{n}\right\} \\
\leq\left(1-a_{n}\right)\left\{\left(1+v_{n} M^{*}\right) d\left(x_{n}, q\right)+\mu_{n}\right\} \\
+a_{n} L\left\{\left(1+v_{n} M^{*}\right) d\left(x_{n}, q\right)+\mu_{n}\right\}
\end{gathered}
$$




$$
\begin{gathered}
\leq\left\{\left(1-a_{n}\right)\left(1+v_{n} M^{*}\right)+a_{n} L\left(1+v_{n} M^{*}\right)\right\} d\left(x_{n}, q\right) \\
+\left(1+a_{n}(L-1)\right) \mu_{n} \\
\leq\left\{\left(1+a_{n}(L-1)\right)+v_{n} M^{*}\left(1+a_{n}(L-1)\right)\right\} d\left(x_{n}, q\right) \\
+\left(1+a_{n}(L-1)\right) \mu_{n} .
\end{gathered}
$$

Thus, by Lemma 1.6 and condition (a), $\lim _{n \rightarrow \infty} d\left(x_{n}, q\right)$ exists for all $q \in F$.

Let $\quad \lim _{n \rightarrow \infty} d\left(x_{n}, q\right)=c$.

Since,

$$
\begin{gathered}
\begin{aligned}
d\left(S^{n} y_{n}, q\right) \leq & d\left(y_{n}, q\right)+v_{n} \zeta\left(d\left(y_{n}, q\right)\right)+\mu_{n} \\
\leq & \left(1+v_{n} M^{*}\right) d\left(y_{n}, q\right)+\mu_{n}
\end{aligned} \\
\leq\left(1+v_{n} M^{*}\right)\left\{\left(1+v_{n} M^{*}\right) d\left(x_{n}, q\right)+\mu_{n}\right\}+\mu_{n} \\
\leq\left(1+v_{n} M^{*}\right)\left(1+v_{n} M^{*}\right) d\left(x_{n}, q\right)+\left(2+v_{n} M^{*}\right) \mu_{n} .
\end{gathered}
$$

Using, (2.1.2),

$$
\lim \sup d\left(S^{n} y_{n}, q\right) \leq c .
$$

Similarly,

$$
\limsup _{n \rightarrow \infty} d\left(T^{n} x_{n}, q\right) \leq c .
$$

In addition,

$$
c=\lim _{n \rightarrow \infty} d\left(x_{n+1}, \mathrm{q}\right)=\lim _{n \rightarrow \infty} d\left(W\left(T^{n} x_{n}, S^{n} y_{n}, a_{n}\right), \mathrm{q}\right) .
$$

With the help of (2.1.3), (2.1.4) and Lemma 1.7,

$$
\lim _{n \rightarrow \infty} d\left(T^{n} x_{n}, S^{n} y_{n}\right)=0 .
$$

On the other hand, since

$$
\left.d\left(x_{n+1}, T^{n} x_{n}\right)=d\left(\mathrm{~W} T^{n} x_{n}, S^{n} y_{n}, a_{n}\right), T^{n} x_{n}\right) \leq a_{n} d\left(S^{n} y_{n}, T^{n} x_{n}\right) .
$$

From (2.1.5),

$$
\lim _{n \rightarrow \infty} d\left(x_{n+1}, T^{n} x_{n}\right)=0 .
$$

Thus, using condition (d),

$$
\lim _{n \rightarrow \infty} d\left(x_{n}, T^{n} x_{n}\right)=0 .
$$

Hence, from (2.1.6) and (2.1.7),

$$
\lim _{n \rightarrow \infty} d\left(x_{n+1}, x_{n}\right)=0 .
$$

Now,

$$
\begin{aligned}
d\left(y_{n}, x_{n}\right) & =d\left(\mathrm{~W}\left(x_{n}, T^{n} x_{n}, \mathrm{~b}_{n}\right), x_{n}\right) \\
& \leq\left(1-b_{n}\right) d\left(x_{n}, x_{n}\right)+b_{n} d\left(T^{n} x_{n}, x_{n}\right) .
\end{aligned}
$$

Using (2.1.7),

$$
\lim _{n \rightarrow \infty} d\left(y_{n}, x_{n}\right)=0 .
$$

Also, $\quad d\left(x_{n+1}, y_{n}\right) \leq d\left(x_{n+1}, x_{n}\right)+d\left(y_{n}, x_{n}\right)$

Using (2.1.8) and (2.1.9),

$$
\lim _{n \rightarrow \infty} d\left(x_{n+1}, y_{n}\right)=0 \text {. }
$$

Now,

$d\left(x_{n+1}, S^{n} y_{n}\right) \leq d\left(x_{n+1}, x_{n}\right)+d\left(x_{n}, T^{n} x_{n}\right)+d\left(T^{n} x_{n}, S^{n} y_{n}\right)$.

By (2.1.5), (2.1.7) and (2.1.8),

$\lim _{n \rightarrow \infty} d\left(x_{n+1}, S^{n} y_{n}\right)=0$.

Thus,

$d\left(x_{n}, S^{n} x_{n}\right) \leq d\left(x_{n}, x_{n+1}\right)+d\left(x_{n+1}, S^{n} y_{n}\right)+d\left(S^{n} y_{n}, S^{n} x_{n}\right)$

$$
\leq d\left(x_{n}, x_{n+1}\right)+d\left(x_{n+1}, S^{n} y_{n}\right)+L d\left(y_{n}, x_{n}\right)
$$

So, (2.1.8), (2.1.9) and (2.1.11) gives

$\lim _{n \rightarrow \infty} d\left(x_{n}, S^{n} x_{n}\right)=0$.

Then,

$$
\begin{gathered}
\quad d\left(x_{n+1}, T x_{n+1}\right) \leq d\left(x_{n+1}, T^{n+1} x_{n+1}\right)+d\left(T^{n+1} x_{n+1}, T^{n+1} x_{n}\right) \\
\quad+d\left(T^{n+1} x_{n}, T x_{n+1}\right) \\
\leq d\left(x_{n+1}, T^{n+1} x_{n+1}\right)+L d\left(x_{n+1}, x_{n}\right)+L d\left(T^{n} x_{n}, x_{n+1}\right) \\
=d\left(x_{n+1}, T^{n+1} x_{n+1}\right)+L d\left(x_{n+1}, x_{n}\right)+\operatorname{La} a_{n} d\left(T^{n} x_{n}, S^{n} y_{n}\right) .
\end{gathered}
$$

It follows from (2.1.5), (2.1.7) and (2.1.8) that $\lim _{n \rightarrow \infty} d\left(x_{n}, T x_{n}\right)=0$

Finally,

$$
\begin{aligned}
& d\left(x_{n+1}, S x_{n+1}\right) \leq d\left(x_{n+1}, S^{n+1} x_{n+1}\right)+d\left(S^{n+1} x_{n+1}, S x_{n+1}\right) \\
& \leq d\left(x_{n+1}, S^{n+1} x_{n+1}\right)+L d\left(S^{n} x_{n+1}, x_{n+1}\right) \\
& \leq d\left(x_{n+1}, S^{n+1} x_{n+1}\right)+L\left[d\left(S^{n} x_{n+1}, S^{n} y_{n}\right)+d\left(S^{n} y_{n}, x_{n+1}\right)\right] \\
& \leq d\left(x_{n+1}, S^{n+1} x_{n+1}\right)+L\left[L d\left(x_{n+1}, y_{n}\right)+d\left(S^{n} y_{n}, x_{n+1}\right)\right]
\end{aligned}
$$

implies by using (2.1.10), (2.1.11) and (2.1.12) that $\lim _{n \rightarrow \infty} d\left(x_{n}, S x_{n}\right)=0$.

Theorem 2.2 Let $X, C, T, S, F,\left\{a_{n}\right\},\left\{b_{n}\right\}$ and $\left\{x_{n}\right\}$ be as in Lemma 2.1. If $I-T$ and $I-S$ are demiclosed with respect to zero, then $\left\{x_{n}\right\} \Delta$-converges to a point of $F$.

Proof. Let $q \in F$. Then by Lemma 2.1, $\lim _{n \rightarrow \infty} d\left(x_{n}, q\right)$ exists for all $q \in F$. Thus $\left\{x_{n}\right\}$ is bounded. From Lemma 2.1, we have $\lim _{n \rightarrow \infty} d\left(x_{n}, T x_{n}\right)=0=\lim _{n \rightarrow \infty} d\left(x_{n}, S x_{n}\right)$.

Firstly, it is to be prove that $\omega_{\Delta}\left(x_{n}\right) \subset F$. Let $u \in \omega_{\Delta}\left(x_{n}\right)$, then there exists a subsequence $\left\{u_{n}\right\}$ of $\left\{x_{n}\right\}$ such that $A\left(\left\{u_{n}\right\}\right)=\{u\}$. Then there exists a subsequence $\left\{v_{n}\right\}$ of $\left\{u_{n}\right\}$ such that $\Delta-\lim _{n} v_{n}=v$ for some $v \in C$. Also $I-T$ and $I-S$ are demiclosed with respect to zero, therefore $\mathrm{Tv}=\mathrm{v}=$ Sv, which means that $v \in F$. By Lemma 2.1, $\lim _{n \rightarrow \infty} d\left(x_{n}, v\right)$ exists. Now, it is claimed that $u=v$. Assume on the contrary that $u \neq v$. Then by the uniqueness of asymptotic centers, 


$$
\begin{aligned}
\lim _{n \rightarrow \infty} \sup & d\left(v_{n}, v\right)<\lim _{n \rightarrow \infty} \sup d\left(v_{n}, u\right) \\
\leq & \lim _{n \rightarrow \infty} \sup d\left(u_{n}, u\right)<\lim _{n \rightarrow \infty} \sup d\left(u_{n}, v\right) \\
= & \lim _{n \rightarrow \infty} \sup d\left(x_{n}, v\right)=\lim _{n \rightarrow \infty} \sup d\left(v_{n}, v\right),
\end{aligned}
$$

a contradiction. Thus $u=v \in F$ and hence $\omega_{\Delta}\left(x_{n}\right) \subset F$.

Now, it is to be prove that the sequence $\left\{x_{n}\right\} \Delta$-converges to a point of $F$, I show that $\omega_{\Delta}\left(x_{n}\right)$ consists of exactly one point. Let $\left\{u_{n}\right\}$ be a subsequence of $\left\{x_{n}\right\}$. Then there exists a subsequence $\left\{v_{n}\right\}$ of $\left\{u_{n}\right\}$ such that $\Delta-\lim _{n} v_{n}=v$ for some $v \in C$. Let $A\left(\left\{u_{n}\right\}\right)=\{u\}$ and $A\left(\left\{x_{n}\right\}\right)=\{x\}$. It is already proved that $u=v \in F$. Finally, it is claimed that $x=v$. If is not true, then existence of $\lim _{n \rightarrow \infty} d\left(x_{n}, v\right)$ and uniqueness of asymptotic centre imply that

$$
\begin{aligned}
\lim _{n \rightarrow \infty} \sup d\left(v_{n}, v\right) & <\lim _{n \rightarrow \infty} \sup d\left(v_{n}, x\right) \leq \lim _{n \rightarrow \infty} \sup d\left(x_{n}, x\right) \\
& <\lim _{n \rightarrow \infty} \sup d\left(x_{n}, v\right)=\lim _{n \rightarrow \infty} \sup d\left(v_{n}, v\right),
\end{aligned}
$$

a contradiction. Thus $x=v \in F$ and hence $\omega_{\Delta}\left(x_{n}\right)=\{x\}$. Thus, $\left\{x_{n}\right\} \Delta$-converges to a point of $F$.

Now, the strong convergence results for iterative procedure (1.1.6):

Theorem 2.3. Let $\mathrm{X}$ be a complete hyperbolic space and $C, T$, $S, F,\left\{a_{n}\right\},\left\{b_{n}\right\},\left\{x_{n}\right\}$ be as in Lemma 2.1. If $F \neq \phi$, then $\left\{x_{n}\right\}$ converges strongly to a point of $F$ if and only if $\lim _{n \rightarrow \infty} \inf d\left(x_{n}, F\right)=0$, where $d(x, F)=\inf \{d(x, p): p \in F\}$.

Proof. Necessity is obvious. Conversely, suppose that $\lim \inf d\left(x_{n}, F\right)=0$. As proved in Lemma 2.1, we have

$$
d\left(x_{n+1}, p\right) \leq d\left(x_{n}, p\right) \text { for all } p \in F .
$$

This implies that $d\left(x_{n+1}, F\right) \leq d\left(x_{n}, F\right)$, so that $\lim d\left(x_{n}, F\right)$ exists. But by hypothesis $\lim \inf d\left(x_{n}, F\right)=0$

. Therefore $\lim _{n \rightarrow \infty} d\left(x_{n}, F\right)=0$.

Next, it is shown that $\left\{x_{n}\right\}$ is a cauchy sequence in $C$. Let $\varepsilon>0$ be arbitrarily chosen. Since

$\lim _{n \rightarrow \infty} d\left(x_{n}, F\right)=0$, there exists a positive integer $n_{0}$ such that $d\left(x_{n}, F\right)<\frac{\varepsilon}{4} \quad$ for all $n \geq n_{0}$.

In particular, $\inf \left\{d\left(x_{n_{0}}, p\right): p \in F\right\}<\frac{\varepsilon}{4}$. Thus there must exist $p^{*} \in F$ such that

$$
d\left(x_{n_{0}}, p^{*}\right)<\frac{\varepsilon}{2} .
$$

Now for all $m, n \geq n_{0}$,

$$
\begin{aligned}
d\left(x_{n+m}, x_{n}\right) \leq & d\left(x_{n+m}, p^{*}\right)+d\left(p^{*}, x_{n}\right) \\
& \leq 2 d\left(x_{n_{0}}, p^{*}\right)<2\left(\frac{\varepsilon}{2}\right)=\varepsilon .
\end{aligned}
$$

Hence $\left\{x_{n}\right\}$ is a cauchy sequence in a closed subset $C$ of a complete hyperbolic space and so it must converge to a point $q$ in $C$. Now, $\lim _{n \rightarrow \infty} d\left(x_{n}, F\right)=0$, gives that $d(q, F)=0$. Since $\mathrm{F}$ is closed, implies $q \in F$.

Fukhar-ud-din and Khan [3] introduced the concept of condition $\left(A^{\prime}\right)$ as follows:

Two mappings $T, S: C \rightarrow C$ are said to satisfy the condition $\left(A^{\prime}\right)$ if there exists a nondecreasing function $f:[0, \infty) \rightarrow[0$, $\infty$ ) with $f(0)=0, f(r)>0$ for all $r \in(0, \infty)$ such that either

$$
f(d(x, F)) \leq d(x, T x), \text { or } \quad f(d(x, F)) \leq d(x, S x)
$$

for all $x \in C$,

where $d(x, F)=\inf \{d(x, p): p \in F\}$.

By taking $S=T$ in this condition, it reduces to condition(A) of Senter and Doston[4].

Theorem 2.4. Let $\mathrm{X}$ be a complete hyperbolic space and $C, T$, $S, F,\left\{a_{n}\right\},\left\{b_{n}\right\},\left\{x_{n}\right\}$ be as in Lemma 2.1. Let S, T satisfy the condition $\left(A^{\prime}\right)$ and $F \neq \phi$. Then $\left\{x_{n}\right\}$ converges strongly to a point of $F$.

Proof. It has proved in Lemma 2.1 that $\lim _{n \rightarrow \infty} d\left(x_{n}, p\right)$ exists for all $p \in F$. Let this limit be $c$. As proved in Lemma 2.1, we have $d\left(x_{n+1}, p\right) \leq d\left(x_{n}, p\right)$ for all $p \in F$.

This gives that $\inf _{p \in F} d\left(x_{n+1}, p\right) \leq \inf _{p \in F} d\left(x_{n}, p\right)$, which means that $d\left(x_{n+1}, F\right) \leq d\left(x_{n}, F\right)$, so that $\lim _{n \rightarrow \infty} d\left(x_{n}, F\right)$ exists. Again using Lemma 2.1, we have $\lim _{n \rightarrow \infty} d\left(x_{n}, T x_{n}\right)=0=\lim _{n \rightarrow \infty} d\left(x_{n}, S x_{n}\right)$.

From the condition $\left(A^{\prime}\right)$, either

$$
\begin{gathered}
\lim _{n \rightarrow \infty} f\left(d\left(x_{n}, F\right)\right) \leq \lim _{n \rightarrow \infty} d\left(x_{n}, T x_{n}\right)=0, \\
\lim _{n \rightarrow \infty} f\left(d\left(x_{n}, F\right)\right) \leq \lim _{n \rightarrow \infty} d\left(x_{n}, S x_{n}\right)=0 .
\end{gathered}
$$

Hence $\quad \lim _{n \rightarrow \infty} f\left(d\left(x_{n}, F\right)\right)=0$. Since $f:[0, \infty) \rightarrow[0, \infty)$ is a nondecreasing function satisfying $f(0)=0, f(r)>0$ for all $r \epsilon$ $(0, \infty)$, therefore we have $\lim _{n \rightarrow \infty} d\left(x_{n}, F\right)=0$. Now, all the conditions of Theorem 2.3 are satisfied, therefore $\left\{x_{n}\right\}$ converges strongly to a point of $F$.

Theorem 2.5. Let $\mathrm{X}$ be a complete hyperbolic space and $C, T$, $S, F,\left\{a_{n}\right\},\left\{b_{n}\right\},\left\{x_{n}\right\}$ be as in Lemma 2.1. Suppose that one of $\mathrm{S}$ and $\mathrm{T}$ is semi-compact. If $F \neq \phi,\left\{x_{n}\right\}$ converges strongly to a point of $F$.

Proof. From Lemma 2.1, we have $\lim _{n \rightarrow \infty} d\left(x_{n}, T x_{n}\right)=0=\lim _{n \rightarrow \infty} d\left(x_{n}, S x_{n}\right)$. Let one of $\mathrm{S}$ and $\mathrm{T}$ is semi-compact, then there exists a subsequence $\left\{x_{n_{k}}\right\}$ of $\left\{x_{n}\right\}$ such that $\left\{x_{n_{k}}\right\}$ converges strongly to some point $p \in C$. Moreover, using continuity of S and T, we have

$$
\begin{array}{r}
d(p, T p)=\lim _{n \rightarrow \infty} d\left(x_{n_{k}}, T x_{n_{k}}\right)=0, \\
d(p, S p)=\lim _{n \rightarrow \infty} d\left(x_{n_{k}}, S x_{n_{k}}\right)=0 .
\end{array}
$$


Thus, $p \in F$. Again, from Lemma 2.1, $\lim _{n \rightarrow \infty} d\left(x_{n}, p\right)$ exists for all $p \in F$. Since $\lim _{k \rightarrow \infty} d\left(x_{n_{k}}, p\right)=0$.

Therefore, $\quad \lim d\left(x_{n}, p\right)=0$ and therefore $\left\{x_{n}\right\}$ converges strongly to a point of $F$.

\section{REFERENCES}

[1] Sahin, A. and Basarir, M. On the strong convergence of a modified S-iteration process for asymptotically quasinonexpansive mappings in a CAT(0) space, Fixed Point Theory and Applications, vol. 2013, no 12, (2013) , doi:10.1186/1687-1812-2013-12.

[2] Khan, A. R., Fukhar-ud-din, H. and Khan, M. A. An implicit algorithm for two finite families of nonexpansive maps in hyperbolic spaces, Fixed Point Theory Appl., vol.54, (2012), 12 pages.

[3] Fukhar-ud-din, H. and Khan, S. H. 2007 Convergence of iterates with errors of asymptotically quasi nonexpansive mappings and applications, J. Math. Anal. Appl., vol. $328,(2007), 821-829$

[4] Senter, H. F. and Dotson, W. G. Approximating fixed points of nonexpansive mappings, Proc. Amer. Math. Soc., vol. 44, (1974), 375-380.

[5] Schu, J. Weak and strong convergence to fixed points of asymptotically nonexpansive mappings, Bull. Austral. Math. Soc., vol. 43, (1991), 153-159.

[6] Tan, K. K. and Xu, H. K. Fixed point iteration processes for asymptotically nonexpansive mappings, Proc. Amer. Math. Soc., vol. 122, (1994), 733-739.

[7] Goebel, K. and Kirk, W. A. A fixed point theorem for asymptotically nonexpansive mappings, proc. Amer. Math. Soc., vol. 35, no. 1, (1972), 171-174.

[8] Qihou, L. Iterative sequences for asymptotically quasinonexpansive mappings, J. Math. Anal. Appl., vol. 259, (2001), 1-7.

[9] Leustean, L. Nonexpansive iterations in uniformly convex W-hyperbolic spaces. In: Leizarowitz, A, Mordukhovich, BS, Shafrir, I, Zaslavski, A (eds.) Nonlinear Analysis and Optimization I: Nonlinear Analysis. Contemp. Math., vol. 513, pp. 193-209. Am. Math. Soc., Providence (2010)

[10] Basarir, M. and Sahin A., On the strong and $\Delta$ convergence for total asymptotically nonexpansive mappings 0n a CAT(0) space, Carpathian Math. Publ., vol. 5, no 2, (2013), 170-179.

[11] Aggarwal, M. and Chugh, R. Strong and $\Delta$ convergence of Khan et. al. iterative procedure in CAT(0) spaces, Differential Geometry, Functional Analysis and Applications, Narosa Publishing House, New Delhi, 2015, 143-155.
[12] Agarwal, R. P., O'Regan, D. and Sahu D. R., Iterative construction of fixed points of nearly asymptotically nonexpansive mappings, J.Nonlinear Convex Anal., vol. 8, no. 1, (2007), 61-79.

[13] Chugh, R. Preety and Aggarwal, M. Some convergence results for modified S-iterative scheme in Hyperbolic spaces, International Journal of Computer Applications, 80 (6), 2013, 20-23.

[14] Dhompongsa, S. and Panyanak, B. On $\Delta$-convergence theorems in CAT(0) spaces, Comput. Math. Appl., vol 56, (2008), 2572-2579.

[15] Khan S. H. and Jong Kyu Kim, Common fixed points of two nonexpansive mappings by a modified faster iteration scheme, Bull. Korean Math. Soc., vol. 47, no. 5, (2010), 973-985.

[16] Khan, S. H. and Abbas, M. Strong and $\Delta$-convergence of some iterative schemes in CAT(0) spaces, Computers and Mathematics with Applications, vol. 61, (2011), 109. 116.

[17] Khan, S. H., Cho, Y. J. and Abbas, M. Convergence to common fixed points by a modified iteration process, J. Appl math. Comput. Vol. 35, (2011), 607-616.

[18] Chang, S. S., Wang, L., Joseph Lee, H. W. and Chan, C. K. Demiclosed principle and $\Delta$-convergence theorems for total asymptotically nonexpansive mappings in CAT(0) Spaces, Appl. Math. Comput., vol. 219, (2012), 2611-2617.

[19] Diaz, S. B. and Metcalf, F. B. On the structure of the set of sequential limit points of successive approximations, Bull. Amer. Math. Soc., vol. 73, (1967), 516-519.

[20] Lim, T.C. Remarks on some fixed point theorems, Proc. Amer. Math. Soc., vol. 60, (1976), 179-182.

[21] Shimizu, T. and Takahashi, W. Fixed points of multivalued mappings in certain convex metric spaces, Topol. Methods Nonlinear Anal., vol. 8, (1996), 197. 203.

[22] Kuczumow, T. An almost convergence and its applications, Ann. Univ. Mariae Curie-Sklodowska, Sect. A., vol. 32, (1978),79-88.

[23] Kohlenbach, U. Some logical metatheorems with applications in functional analysis, Trans. Amer. Math. Soc., vol. 357(2005), 89-128.

[24] Petryshyn, W. V. and Williamson, T. E. Strong and weak convergence of the sequence of successive approximations for quasi-nonexpansive mappings, J. math. Anal. Appl., vol. 43, (1973), 459-497.

[25] Takahashi, W. A convexity in metric spaces and nonexpansive mapping, Kodai Math. Sem. Rep., vol. 22, (1970), 142-149. 